Int. J. Odontostomat.,

15(4):823-826, 2021.

\title{
How Difficult is it for Patients Having Oral Ulcers to Get Diagnosed?
}

\author{
¿Qué tan Difícil es el Diagnóstico para los Pacientes con Úlceras Orales?
}

\author{
Ayat Gamal-AbdeINaser; Enji Ahmed Mahmoud',2; Mai Zakareia Ibrahium ${ }^{1}$ \& Soheir Gaafar ${ }^{1}$
}

GAMAL-ABDELNASER, A.; MAHMOUD, E. A.; IBRAHIUM, M. Z. \& GAAFAR, S. How difficult is it for patients having oral ulcers to get diagnosed?. Int. J. Odontostomat., 15(4):823-826, 2021.

\begin{abstract}
Oral ulcers cause high levels of impairment of the patients' quality of life. Therefore, patients having oral ulcers visit clinicians while seeking treatment. This study aims to investigate the extent of patients' suffering till reaching the correct clinician specialty, and therefore, proper diagnosis and treatment. The study included 62 diagnosed oral ulcer patients. They filled a questionnaire about previously visited clinicians and their specialties, causes of their referral and Oral Health Impact Profile-14 indicating their quality of life. The study revealed that participants visit a mean number of 2.93 clinicians before reaching a specialist. Furthermore, the number of the visited clinicians was positively correlated to the impact of the oral ulcer on quality of life. The study reflects the degree of unnecessary suffering of patients having oral ulcers due to unnecessary delay of diagnosis. It, thereby, highlights the necessity for higher awareness about Oral Medicine specialty among medical practitioners and among general population as well.
\end{abstract}

KEY WORDS: OHRQoL, oral health-related quality of life, OHIP-14, oral health impact profile.

\section{INTRODUCTION}

Many patients believe dentistry is concerned with dental problems only; especially with the interfering areas of interest between oral medicine on one side and dermatology and otolaryngology specialties on the other side (Miller et al., 2001; Farah et al., 2008). Therefore, when complaining of any oral soft tissue lesion, they prefer consulting a physician (Miller et al., 2001; Do et al., 2014).

Consulting the physicians of the incorrect specialties and incorrect referral patterns, both can cause higher cost expenses, delay of diagnosis and treatment causing more time of patient's suffering (15 months in average), and poorer prognosis (Haberland et al., 1999; Farah et al.).

As most types of oral ulcers have significant impact on the patients' oral health-related quality of life (OHRQoL) (AbdelNaser et al., 2021), early diagnosis and treatment of the condition is considered crucial (Miller et al., 2001).
Therefore, this report quantifies the unnecessary delay of diagnosis in patients having oral ulcers by exploring the number and specialties of physicians consulted, the relation of the extent of OHRQoL impairment and the visited physicians, and -if referredthe pattern and necessity of referral.

\section{MATERIAL AND METHOD}

The current cross-sectional study was held in the Faculty of Dentistry, Cairo University, Egypt. The survey included 62 patients having oral ulcers; as a subgroup in a larger study (AbdelNaser et al.). The study included adult patients currently having any type of oral ulcers. Patients having severe problems with mouth opening were excluded.

The study was approved by the research ethics committee of the faculty of Dentistry, Cairo University.

${ }^{1}$ Oral Medicine and Periodontology department, Faculty of Dentistry, Cairo University, Cairo, Egypt.

${ }^{2}$ Oral Medicine and Periodontology department, Faculty of Dentistry, British University in Egypt, Cairo, Egypt.

Received: 2021-07-26 Accepted: 2021-08-30 
After obtaining a signed informed consent, each participant was interviewed to fill a questionnaire about predictor and outcome variables.

The predictors included the type of the oral ulcer that the patient was having [diagnosed based on WHO diagnostic criteria (Kramer et al., 1980)]; and the effect of the oral ulcers on the OHRQoL measured by oral health impact profile (OHIP-14) (Slade, 1997).

The study investigated the following outcomes: (a) the number and specialties of clinicians visited for diagnosing and treating the patient's oral ulcer; (b) association between the number of visited clinicians and OHRQoL associated with the ulcer; and (c) referral causes and necessity whenever the patient was referred to an Oral Medicine specialist.

Data was statistically analyzed using the SPSS software (version 16.0, SPSS Inc., IL, USA). Linear correlation was used to test the correlation between the number of visited physicians and the scores of OHIP-14. All tests were two-sided, and $\mathrm{P}<0.05$ indicates statistical significance.

\section{RESULTS}

The mean age of the 62 participants was 33.5 years $( \pm 16.2)$. The diagnosis was categorized into: reactive ulcers, erythema multiforme (EM), recurrent viral ulcers, pemphigus vulgaris (PV), ulcerative form of oral lichen planus (OLP), recurrent aphthous stomatitis (RAS) and oral cancer. Details of the effect of each type of the ulcers on OHRQoL were clarified (AbdelNaser et al.).

\section{Outcome data.}

a) Number and specialties of clinicians previously visited: The mean number of clinicians visited by all oral ulcer patients was $2.93 \pm 2.08$ (Table I).

The most widely consulted specialty was general dental practitioners (consulted by $46.8 \%$ of the patients), followed by internal medicine specialists (16.1\%), and dermatologists (16.1\%) then general surgeons $(8.1 \%)$, oto-laryngeology specialists $(6.5 \%)$, oral medicine specialists $(4.8 \%)$, dental specialists $(4.8 \%)$, then oncology (3.2\%), and, lastly, rheumatologists (1.6\%), gastroenterology specialists (1.6\%), ophthalmologists $(1.6 \%)$, tropical medicine specialists $(1.6 \%)$, orthopedic surgeons $(1.6 \%)$ and neurologists (1.6\%). A gathered percentage of consulted physicians of all specialties came second as $32.3 \%$.

Patients were remarked to consult the physician who treats their chronic systemic diseases about their oral ulcers. The physicians were also remarked to prescribe treatment for the oral ulcers instead of their referral to a specialist.

b) Association between the number of visited clinicians and OHRQoL:

The number of visited clinicians was positively correlated to the effect of the ulcer on all aspects of OHRQoL except psychological discomfort and handicap (Table II).

c) Cause of referral: From the participants, $59.7 \%$ were referred from other clinician; $78.4 \%$ of them were referred for diagnosis and assessment, $5.4 \%$ were referred for management, $3.2 \%$ for second opinion from a specialist, and $1.6 \%$ for further investigation. Among the referred patients, $5.2 \%$ were misdiagnosed as a more severe condition or malignancy. Upon assessment of all the referred cases, $40.5 \%$ were not indicated for referral.

Table II. The correlation between the number of visited clinicians and the 7 aspects of OHIP-14. Correlation is expressed through correlation coefficient $(r)$

\begin{tabular}{lll}
\hline Variable & $\mathrm{r}$ & $P$-Value \\
\hline Functional Limitation & 0.474 & $0.001^{*}$ \\
Physical Pain & 0.36 & $0.016^{*}$ \\
Psychological discomfort & 0.092 & 0.554 \\
Physical disability & 0.374 & $0.012^{*}$ \\
Psychological Disability & 0.526 & $<0.001^{*}$ \\
Social Disability & 0.335 & $0.026^{*}$ \\
Handicap & 0.205 & 0.182 \\
OHIP-14 & 0.473 & $0.001^{*}$ \\
\hline
\end{tabular}

${ }^{*}$ P-value $<0.05^{* *}$ tested by Pearson correlation coefficient

Table I. The mean number of clinicians visited by patients having each type of oral ulcers.

\begin{tabular}{lllllllll}
\hline Type of oral ulcer & Reactive & EM & RAS & Viral & OLP & PV & Oral & Total \\
\hline $\begin{array}{l}\text { Mean of no. of } \\
\text { clinicians (SD) }\end{array}$ & \multirow{2}{*}{$2.33(1.75)$} & 3.25 & 2.76 & \multirow{2}{*}{$1(0.00)$} & 4.17 & 3.67 & $3(0.000)$ & 2.93 \\
& & $(2.63)$ & $(2.3)$ & & $(1.84)$ & $(2.31)$ & \\
\hline
\end{tabular}

EM: Erythema Multiforme, OLP: Oral Lichen Planus (Ulcerative type), PV: Pemphigus Vulgaris, RAS: Recurrent Aphthous Stomatitis. 


\section{DISCUSSION}

This pilot study investigates the unnecessary delay of diagnosis among a sample of patients having oral ulcers by detecting the specialties of clinicians they consulted. Our results showed that patients having oral ulcers visit a mean number of $2.93 \pm 2.08$ healthcare practitioners before reaching an oral medicine specialist. A previous study (Haberland et al.) reported a lower figure of mean number of $2.2 \pm 1.8$ healthcare practitioners. The higher number reported by the current study may be explained by the difference between the populations of the two studies. The previous study (Haberland et al.) included patients having dental and periodontal diseases; which are well known to be treated by dental practitioners unlike oral lesions.

Our participants preferred to consult in the first place general dental practitioners $(46.8 \%)$ followed by physicians with different specialties $(32.3 \%)$. These are consistent with previous reports (Haberland et al.; Miller et al., 2001) that the main source of referral were from general dental practitioner (42.4\% (Miller et al., 2001) and $55 \%$ (Haberland et al.) followed by medical practitioner, $37.1 \%$ (Miller et al., 2001) and $45 \%$ (Haberland et al.).

To our knowledge, the current study is the first to correlate the impact of oral ulcers on OHRQoL to the previously consulted clinicians. Our results proved that the more the effect of oral ulcer on all OHRQoL aspects except psychological discomfort and handicap, the more the number of clinicians the patient visits. Although PV and OLP come in the second and third places (respectively) on its impairment of OHRQoL after EM, OLP and PV patients reported higher number of visited physicians. This can be explained by the long term chronic courses of OLP and PV; while EM has an acute, short-term and self-limiting course. Patients having OLP and PV are expected to suffer for longer period of time through which they keep visiting different clinicians aiming to reach a relieving treatment.

In other words, the number of previously consulted clinicians can be correlated to the chronicity of the disease, beside its impact on the OHRQoL.

Regarding the patients' referral, $59.7 \%$ of our oral ulcer patients were referred, a much small percentage compared to the previously reported 96.8 $\%$ (Miller et al., 1997). This might reflect better awareness of patients to consult a dentist in the first place for their oral conditions in the time interval of 20 years between the two studies.

The most striking of our results was the percentage of unnecessary referrals. Above $40 \%$ of the referred oral ulcer patients were to be diagnosed and managed by a general dental practitioner in primary healthcare centers. When practitioners in primary healthcare facilities are competent, patients with simple conditions will be diagnosed and managed in shorter time and with less costs. It will also improve the OHRQoL, as the time of suffering from the oral condition will be shortened (Do et al.).

\section{CONCLUSION}

Patients having oral ulcers lead a long journey to reach diagnosis. It includes consulting physicians of wrong specialties, being misdiagnosed, administering wrong treatments, delaying their correct treatments, and being unnecessarily referred. Higher awareness about the Oral Medicine specialty may have saved them much of this suffering.

GAMAL-ABDELNASER, A.; MAHMOUD, E. A.; IBRAHIUM, M. Z. \& GAAFAR, S. ¿Qué tan difícil es el diagnóstico para los pacientes con úlceras orales? Int. J. Odontostomat., 15(4): 823-826, 2021.

RESUMEN: Las úlceras orales y su diagnóstico tardío causan un nivel de deterioro significativo en la calidad de vida de los pacientes. Este estudio tuvo como objetivo investigar el nivel de sufrimiento de los pacientes hasta llegar a la especialidad clínica y lograr un diagnóstico y tratamiento adecuado. El estudio incluyó a 62 pacientes diagnosticados con úlcera oral. Los pacientes completaron un cuestionario sobre los médicos consultados previamente, las especialidades, las causas de su derivación y el Perfil de Impacto en la Salud Oral-14, que refleja su calidad de vida. El estudio reveló que los participantes visitaron una media de 2,93 médicos antes de consultar con un especialista. Además, el número de médicos visitados se correlacionó positivamente con el impacto que tiene la úlcera oral en la calidad de vida. El estudio refleja el grado de sufrimiento innecesario de los pacientes que presentan úlceras orales debido a un diagnóstico tardío. Por lo tanto, se destaca la necesidad de una mayor conciencia sobre la especialidad de medicina oral entre los médicos y también de la población en general.

PALABRAS CLAVE: OHRQoL, calidad de vida relacionada con la salud oral, OHIP-14, perfil de impacto en la salud oral 


\section{REFERENCES}

AbdelNaser, A. G.; Mahmoud, E. A.; Ibrahium, M. Z. \& Gaafar, S. Relation of oral ulcers to quality of life: a cross-sectional study. Tanta Dent. J., 17:168-82, 2021

Do, L. G.; Spencer, A. J.; Dost, F. \& Farah, C. S. Oral mucosal lesions: findings from the Australian National Survey of Adult Oral Health. Aust. Dent. J., 59(1):114-20, 2014.

Farah, C. S.; Simanovic, B. \& Savage, N. W. Scope of practice, referral patterns and lesion occurrence of an oral medicine service in Australia. Oral Dis., 14 (4):367-75, 2008.

Haberland, C. M.; Allen, C. M. \& Beck, F. M. Referral patterns, lesion prevalence, and patient care parameters in a clinical oral pathology practice. Oral Surg. Oral Med. Oral Pathol. Oral Radiol. Endod., 87(5):583-8, 1999.

Kramer, I. R.; Pindborg, J. J.; Bezroukov, V. \& Infirri, J. S. Guide to Epidemiology and Diagnosis of Oral Mucosal Diseases and Conditions. Geneve, World Health Organization, Community Dentistry and Oral Epidemiology, 1980.

Miller, C. S.; Epstein, J. B.; Hall, E. H. \& Sirois, D. Changing oral care needs in the United States: The continuing need for oral medicine. Oral Surg. Oral Med. Oral Pathol. Oral Radiol. Endod., 91(1):34-44, 2001.

Miller, C. S.; Hall, E. H.; Falace, D. A.; Jacobson, J. J.: Lederman, D. A. \& Segelman, A. E. Need and Demand for Oral Medicine Services in 1996. A report prepared by the Subcommittee on Need and Demand for Oral Medicine Services, a subcommittee of the Specialty Recognition Committee, American Academy of Oral Medicine. Oral Surg. Oral Med. Oral Pathol. Oral Radiol. Endod., 84(6):630-4, 1997.

Slade, G. D. Derivation and validation of a short-form oral health impact profile. Community Dent. Oral Epidemiol., 25(4):284-90, 1997.
Corresponding author:

Ayat Gamal-AbdeINaser

Faculty of Dentistry

Cairo University

11 Saray AL Manial Street

11562

EGYPT

ORCID: 0000-0003-3564-8539

E-mail: ayat.gamal@dentistry.cu.edu.eg 